\title{
MEMORY EFFECTS IN THE PRODUCTION OF BENZENE FOR RADIOCARBON DATING
}

\author{
C J RADNELL* and A B MULLER** \\ Laboratory of Isotope Geochemistry, Department of Geosciences, \\ University of Arizona, Tucson, Arizona 85721
}

\begin{abstract}
The use of materials having high levels of ${ }^{14} \mathrm{C}$ activity (up to 113 times the activity of modern carbon) enabled a quantitative analysis of the magnitude and sites of memory occurring in the routine synthesis of benzene, via lithium carbide, for radiocarbon dating. Memory may be expressed as the percentage or fractional contribution of carbon from sources other than the original sample in this synthesis. Although tritium and radon contamination have also been found, the major site of memory was the inner surface of the stainless steel reaction vessel used for lithium carbide production. Up to 1 percent memory has been found there under extreme conditions in the routine dating system at Harwell. Values of half to one-third this size were more usual, but even etching and scouring the inner surface of the reaction vessel reduced the memory only by a factor of four. This lower limit is believed to exist because of the carburization and decarburization of steel which occurs at the temperature required for the production of lithium carbide. The levels of memory found are of the same order as the levels of significance associated with present radiocarbon techniques. With the accuracy and extended chronologies expected from direct ${ }^{14} \mathrm{C}$ : measurement by accelerator techniques, these levels of memory become increasingly important in the preparation of acetylene and pyrolitic graphite (via lithium carbide) used as target materials. This effect, however, can be limited by lowering the temperature of the carbide reaction stage or by lining or impregnating the lithium carbide reaction vessel with some carbon-impermeable alloy or material.
\end{abstract}

Approximately one-half the radiocarbon laboratories utilize liquid scintillation counting or both liquid scintillation and gas counting. Liquid scintillation systems seem to be preferred in new radiocarbon laboratories and constitute approximately half of the dates published in Radiocarbon. Analysis of the memory effects in liquid scintillation systems is, therefore, of wide interest.

If, as now seems likely, the tandem accelerator radiocarbon technique will borrow part of the liquid scintillation sample preparation technique, a rigorous assessment of memory effect in sample preparation is especially timely.

The use of samples artificially enriched in ${ }^{14} \mathrm{C}$ amplifies any system's memory and allows quantitative inferences to be made of its effect under normal operation. Such results will also aid the design of micropreparation systems to be used with accelerator dating.

\section{Experiments and results}

Contamination affecting a sample during preparation may be classified into two groups: 1) that which is acquired from outside the preparation system, and 2) contamination from within the system, originating from a sample (or samples) previously synthesized. This second type is usually called a system memory effect.

* Formerly at Research Laboratory for Archaeology and the History of Art, 6 Keble Road, Oxford $\mathrm{OX}_{1}{ }_{3} \mathrm{QJ}$ and ${ }^{14} \mathrm{C} /$ Tritium Measurement Laboratory, Building 10.46, AERE Harwell, Didcot, OXON OX ${ }_{11}{ }_{0} \mathrm{RA}$, United Kingdom

** Formerly at Laboratoire de Géologie Dynamique, Université de Pierre et Marie Gurie (Paris IV), 4, place Jussieu, 85230 Paris, France 
A simple mass balance describes the influence of these two types of contamination upon the actual specific activity that is measured for a sample:

$$
A_{m}=A_{s}(1-(f+g))+A_{M} f+A_{c} g
$$

where $A_{m}$ is the measured specific activity of a sample (cpm/g $\mathrm{C}_{6} \mathrm{H}_{6}$ ),

$A_{s}$ is the actual specific activity of that portion of the benzene derived only from the sample $\left(\mathrm{cpm} / \mathrm{g} \mathrm{C}_{6} \mathrm{H}_{6}\right)$,

$A_{M}$ is the specific activity of the benzene synthesized from samples other than the one currently being prepared (cpm/ $\left.\mathrm{g} \mathrm{C}_{6} \mathrm{H}_{6}\right)$,

$A_{c}$ is the specific activity of any external contaminant (cpm/g $\mathrm{C}_{6} \mathrm{H}_{6}$ ),

f is the fraction of the mass of benzene from samples other than the sample currently being synthesized (dimensionless),

$g$ is the fraction of external contamination (dimensionless),

$(\mathrm{l}-(\mathrm{f}+\mathrm{g}))$ is the fraction of benzene synthesized from the actual sample (dimensionless).

The behavior of this equation under various parametric constraints is presented in figures 1 to 3 .

In this paper, we deal primarily with memory effects in the lithium carbide reaction vessel and in the catalyst used for the trimerization of acetylene into benzene. In this system, it is also assumed that every care has been taken to eliminate the effects of 1) remnant carbon from incomplete combustion of previous samples prior to carbide production, 2) radon and tritium from contaminated water used in the hydrolyzation step, and 3) radon contaminated lithium metal (eg, Pearson and others, 1977).

In an initial experiment designed to determine sites in the benzene synthesis process that are susceptible to memory, a benzene sample containing 28 times the modern natural ${ }^{14} \mathrm{C}$ activity was converted to carbon dioxide and resynthesized to benzene. Six samples of "infinitely old" oxalic acid were then converted to benzene in the same system. In order to evaluate the memory effects in both the carbon dioxide production phase and the benzene synthesis phase of preparation, these background

Fig 1.

Fig 2.

Fig 3 .
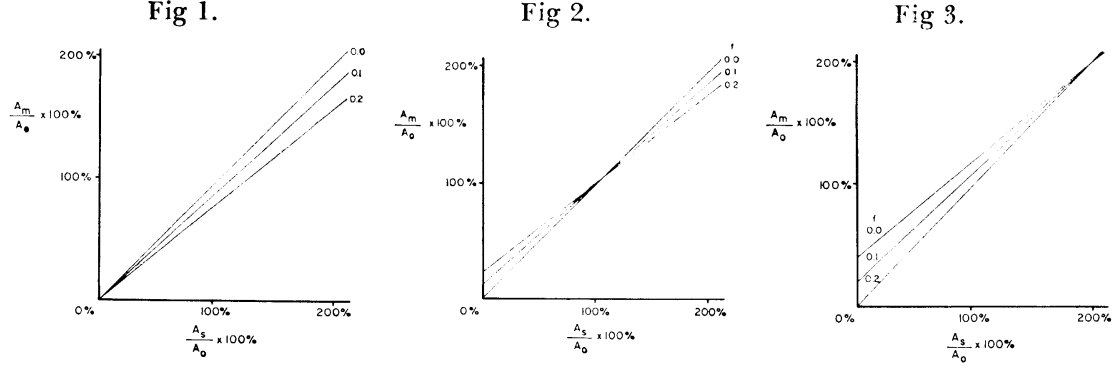

Measured activity versus actual activity of samples influenced to various degrees (ie, $\mathbf{f}=0.0,0.1$, and 0.2 ) by a memory component. Fig 1 . Infinitely old memory component. Fig 2. Memory component of modern activity. Fig 3. Memory component of twice modern activity. 
samples were converted to benzene in the reverse order in which they were combusted. That is, sample HAR-1409 was the last carbon dioxide produced in this experiment but the first to follow the highly active sample in the lithium carbide reaction vessel ( $c f$ table 1, fig 4).

TABLE 1

Results of initial experiment to locate the sites of memory in the benzene synthesis system

\begin{tabular}{ccccc}
\hline $\begin{array}{c}\text { Harwell } \\
\text { sample } \\
\text { no. }\end{array}$ & Sample type & $\begin{array}{c}\text { Weight of } \\
\mathrm{C}_{6} \mathrm{H}_{6}(\mathrm{~g})\end{array}$ & $\begin{array}{c}\text { Total activity } \\
(\mathrm{cpm} \pm 1 \sigma)\end{array}$ & $\begin{array}{c}\text { Net specific activity } \\
\left(\mathrm{dpm} / \mathrm{g} \mathrm{C}_{6} \mathrm{H}_{6} \pm 1 \sigma\right)\end{array}$ \\
\hline HAR-1403 & $\begin{array}{c}\text { Active } \mathrm{C}_{6} \mathrm{H}_{6} \\
\text { Background }\end{array}$ & 6.1000 & $2140 \pm 7$ & $350 \pm 1$ \\
HAR-1404 & 5.2213 & $9.68 \pm 0.13$ & $0.30 \pm 0.05$ \\
oxalic acid & 5.7294 & $9.50 \pm 0.09$ & $0.22 \pm 0.04$ \\
HAR-1405 & $\begin{array}{c}\text { Background } \\
\text { oxalic acid }\end{array}$ & 5.8786 & $9.09 \pm 0.09$ & $0.12 \pm 0.04$ \\
HAR-1406 & $\begin{array}{c}\text { Background } \\
\text { oxalic acid }\end{array}$ & 5.0064 & $9.40 \pm 0.06$ & $0.22 \pm 0.03$ \\
HAR-1407 & $\begin{array}{c}\text { Background } \\
\text { oxalic acid } \\
\text { Background } \\
\text { oxalic acid }\end{array}$ & 6.6162 & $9.73 \pm 0.07$ & $0.25 \pm 0.03$ \\
HAR-1409 & $\begin{array}{c}\text { Background } \\
\text { oxalic acid }\end{array}$ & 5.0098 & $12.21 \pm 0.07$ & $1.18 \pm 0.05$ \\
\hline
\end{tabular}

As apparent from figure 4, sample HAR-1409 (which counted more than $20 \sigma$ above background) has been most affected by the active sample which preceded it in the lithium reactor. Even the subsequent samples in the reaction vessel, HAR-1408 and HAR-1407, are 8 and $7 \sigma$ above background. Since an insufficient number of samples were run to allow the count rate to become equal to background, it is not clear whether sample HAR-1406 (which counts $3 \sigma$ above background) is influenced exclusively by ${ }^{14} \mathrm{C}$ activity from the lithium reactor-trimerization catalyst process or that some ${ }^{14} \mathrm{C}$ activity has been incorporated from the sample combustion process. The memory effect observed in samples HAR-1404 and HAR-1405 was caused by the incomplete removal of unoxidized sample from the combustion system. The principal source(s) of memory in a thoroughly cleaned system is, therefore, on the lithium reactor-trimerization catalyst side of the process.

In an experiment to test the memory of the vanadium pentoxide trimerization catalyst, which is re-used for up to 100 samples, a $10 \mathrm{~g}$ sample of benzene, having an activity 28 times modern carbon, was evaporated onto the catalyst at $-196^{\circ} \mathrm{C}$. When all the benzene had been adsorbed onto the catalyst, as does benzene produced during the trimerization of acetylene, the catalyst was warmed to $20^{\circ} \mathrm{C}$ and left to stand for 2 hours. The benzene was then recovered in the routine manner: heating the catalyst to $350^{\circ} \mathrm{C}$ under vacuum for 4 hours with the benzene condensing in a liquid nitrogen trap. The next step was to adsorb and desorb, as above, a $10 \mathrm{~g}$ sample of benzene near background ${ }^{14} \mathrm{C}$ activity. Before adsorption, its activity was $0.11 \pm 0.05 \mathrm{dpm} / \mathrm{g} \mathrm{C}_{6} \mathrm{H}_{6}$, and after desorption, $0.13 \pm 0.07 \mathrm{dpm} / \mathrm{g} \mathrm{C}_{6} \mathrm{H}_{6}$. The trimerization catalyst 
therefore, had no memory effects when it underwent such routine cleaning procedures.

In light of this result the most likely source of memory observed in the benzene synthesis portion of the preparation line in the initial experiment is the lithium carbide reaction vessel. At the high temperatures used in the production of lithium carbide $\left(\mathrm{ca} 600^{\circ} \mathrm{C}\right)$ the stainless steel of the reaction vessel undergoes carburization (migration of elemental carbon into the steel structure). This process can establish in the steel a reservoir of carbon derived from previous samples prepared in the systems (Agarwala and others, 1970). Extensive studies of stainless steel in nuclear reactor cooling systems have shown that, in the presence of liquid metals such as sodium or lithium, stainless steel undergoes both carburization and decarburization at $500^{\circ} \mathrm{C}$ and above. This occurs primarily as a function of the carbon gradient within the container surface and carbon content of the molten alkali metal (eg, Natesan and Kassner, 1970; Pulham, Hubberstey, and Down, 1977). Although the reaction vessel is low carbon 316 stainless steel, after a few sample preparations the steel is denatured by repeated attacks from molten lithium to such an extent that the special properties of stainless steel are lost. A experiment was conducted at Harwell to determine the extent of the contribution of carbon from the reaction vessel by this mechanism.

Samples of benzene of a known specific activity $(1415 \pm 5 \mathrm{dpm} / \mathrm{g}$ $\mathrm{C}_{6} \mathrm{H}_{6}$ ) were oxidized and resynthesized until a resulting benzene sample

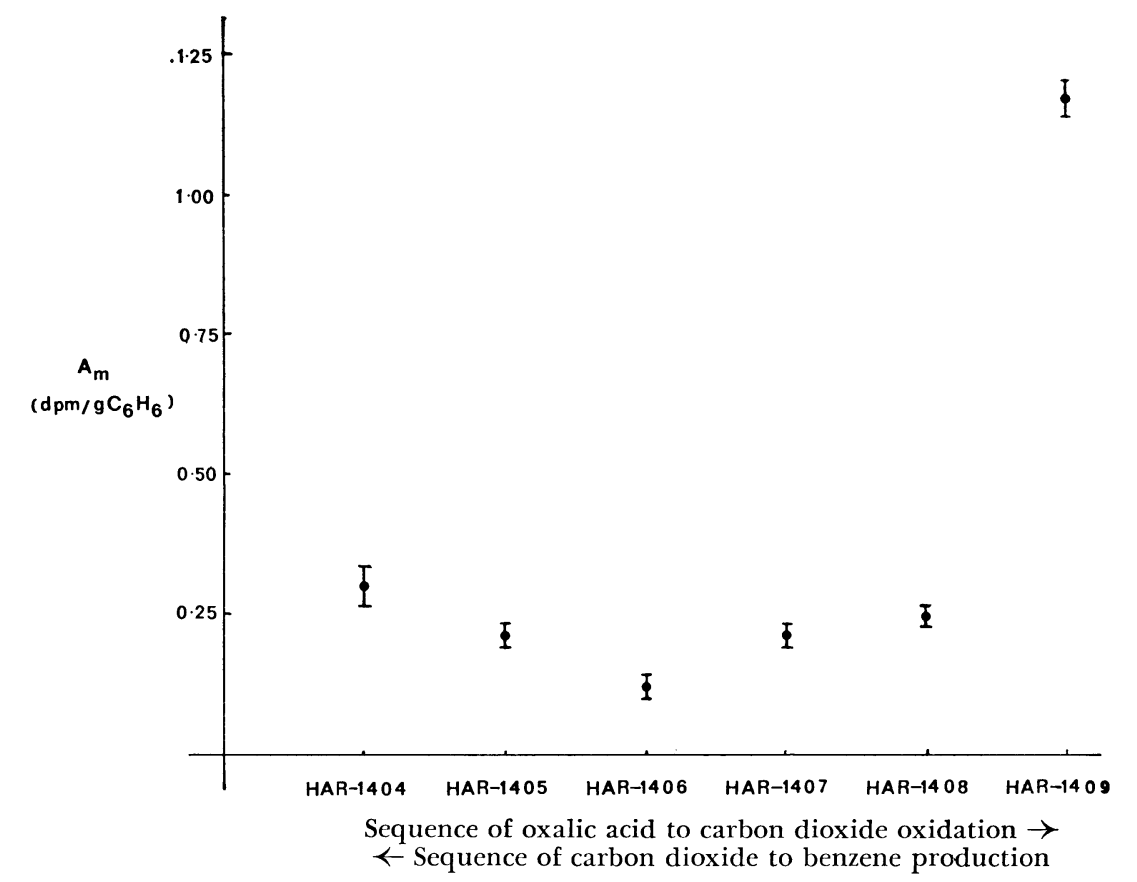
table 1). 
TABLE 2

The extent of memory from the stainless steel reaction vessel in routine sample preparations and in sample preparations using reaction vessels having inner surfaces which have been attacked by repeated exposure to molten lithium

\begin{tabular}{|c|c|c|c|c|c|}
\hline $\begin{array}{l}\text { Harwell } \\
\text { sample } \\
\text { no. }\end{array}$ & Sample type & $\begin{array}{l}\text { Weight of } \\
\mathrm{C}_{6} \mathrm{H}_{6}(\mathrm{~g})\end{array}$ & $\begin{array}{c}\text { Total activity } \\
(\mathrm{cpm} \pm 1 \sigma)\end{array}$ & $\begin{array}{c}\text { Net specifiic } \\
\text { activity } \\
\left(\mathrm{dpm} / \mathrm{g} \mathrm{C}_{6} \mathrm{H}_{8} \pm 1 \sigma\right)\end{array}$ & f \\
\hline $\left.\begin{array}{l}\text { HAR-2202 } \\
\text { HAR-2203 } \\
\text { HAR-2204 }\end{array}\right\}$ & $\begin{array}{l}\text { Active } \mathrm{C}_{6} \mathrm{H}_{6} \\
\text { Background } \\
\text { oxalic acid }\end{array}$ & $\begin{array}{l}6.1000 \\
2.0018 \\
2.3121\end{array}$ & $\begin{array}{l}6050 \pm 15 \\
9.91 \pm 0.18 \\
6.73 \pm 0.13\end{array}$ & $\begin{array}{l}1416 \pm 5 \\
2.03 \pm 0.20 \\
\cong \text { Background }\end{array}$ & 0.0014 \\
\hline $\left.\begin{array}{l}\text { HAR-2221 } \\
\text { HAR-2222 } \\
\text { HAR-2223 }\end{array}\right\}$ & $\begin{array}{l}\text { Active } \mathrm{C}_{6} \mathrm{H}_{6} \\
\text { Background } \\
\text { oxalic acid }\end{array}$ & $\begin{array}{l}6.9000 \\
2.1212 \\
2.2437\end{array}$ & $\begin{array}{r}5150 \pm 10 \\
15.48 \pm 0.32 \\
6.52 \pm 0.09\end{array}$ & $\begin{array}{c}1415 \pm 5 \\
6.06 \pm 0.27 \\
\text { Background }\end{array}$ & 0.0043 \\
\hline $\left.\begin{array}{l}\text { HAR }-2245 \\
\text { HAR-2246 } \\
\text { HAR-2247 }\end{array}\right\}$ & $\begin{array}{l}\text { Active } \mathrm{C}_{6} \mathrm{H}_{6} \\
\text { Background } \\
\text { oxalic acid }\end{array}$ & $\begin{array}{l}5.2000 \\
2.9995 \\
2.3332\end{array}$ & $\begin{array}{r}5215 \pm 10 \\
12.09 \pm 0.30 \\
6.54 \pm 0.07\end{array}$ & $\begin{array}{c}1420 \pm 5 \\
2.79 \pm 0.18 \\
\text { Background }\end{array}$ & 0.0020 \\
\hline \multicolumn{6}{|c|}{ Measured background $=6.48 \pm 0.20 \mathrm{cpm}$} \\
\hline $\left.\begin{array}{l}\text { HAR-2513 } \\
\text { HAR-2514 } \\
\text { HAR-2515 }\end{array}\right\}$ & $\begin{array}{l}\text { Active alcohol } \\
\text { Background } \\
\text { oxalic acid }\end{array}$ & $\begin{array}{l}6.1839 \\
6.9500 \\
7.0700\end{array}$ & $\begin{array}{r}71.16 \pm 0.34 \\
6.94 \pm 0.05 \\
6.61 \pm 0.08\end{array}$ & $\begin{array}{r}15.01 \pm 0.10 \\
0.17 \pm 0.01 \\
0.10 \pm 0.01\end{array}$ & 0.0103 \\
\hline Measured ba & rround $=6.1$ & $7 \mathrm{cpm}$ & & & \\
\hline
\end{tabular}

showed an activity equal to the initial sample (cf, table 2). This last sample could, therefore, only have been influenced by a memory effect of activity equal to itself, implying that the contaminating reservoir of carbon in the stainless steel is now also at a level of $1415 \pm 5 \mathrm{dpm} / \mathrm{g}$ $\mathrm{C}_{6} \mathrm{H}_{6}$. A series of benzenes were then synthesized from background oxalic acid until these samples showed no memory effect. To remove any surface contamination, the reaction vessel was scoured and etched with $6 \mathrm{~N} \mathrm{HCl}$ between each of the syntheses. Values of $\mathrm{f}$ between 0.0014 and 0.0043 were obtained in the first three replicate experiments.

In the extreme case where the inside surface of the reaction vessel was actually pitted by the repeated attack of molten lithium, a value of $\mathrm{f}=0.0103$ was obtained and a single flushing with a background sample was insufficient to eliminate memory. Evidently, routine surface decontanination was unable to remove particulate carbon from the pits, leaving a source of memory in addition to the carburizationdecarburization process mentioned above.

\section{DISCUSSION}

The effect of memory levels observed in these experiments on the results of routine radiocarbon determinations is best illustrated by showing the maximum possible memory obtainable under normal operating conditions. Such a situation might arise if a series of 1964-1965 terrestrial plant samples having twice modern activity $\left(17.5 \mathrm{cpm} / \mathrm{g} \mathrm{C}_{6} \mathrm{H}_{6}\right.$ in this counting system) are followed by an "infinitely" old sample. Table 3 shows that the greatest fractional memory observed between 
preparations separated by routine scouring and $6 \mathrm{~N} \mathrm{HCl} \mathrm{etching}(\mathrm{f}=0.0043)$ would impart an excess activity of $0.09 \mathrm{cpm} / \mathrm{g} \mathrm{C}_{6} \mathrm{H}_{6}(17.5 \times 0.0043)$, or $0.35 \mathrm{cpm}(4 \sigma)$ above background. An infinitely old sample would have an apparent age of $38,000+2600$ radiocarbon years BP under these conditions. Under more adverse conditions, such as in the experiment in which the inside surface of the reaction vessel was no longer completely smooth, $\mathrm{f}=0.0103$ and the memory effect contributes $0.72 \mathrm{cpm}$ above background $(8 \sigma)$. In such a case, an infinitely old sample would have an apparent age of $31,000+1000$ years BP.

Although memory effects do occur under these extreme conditions, their magnitude should become negligible when a sound reaction vessel is thoroughly cleaned both chemically and mechanically and when expected ${ }^{14} \mathrm{C}$ activity of samples is considered in planning their sequence through the preparation system. (For example, a sample with 50 percent modern activity preceded by one of 60 percent modern would acquire only a $0.08 \pm 0.09 \mathrm{cpm}$ excess count rate in a $4 \mathrm{~g}$ benzene sample, or an apparent age of $49,000_{-}^{+} \infty 000$ years $\left.f=0.0043\right)$.

The principal impact of these results lies in the potential application of the lithium carbide technique in preparing acetylene gas or pyrolitic graphite for source materials in the mass spectrometric analysis of ${ }^{14} \mathrm{C}$ by tandem accelerators. With anticipated precisions on the order of $\pm 2 \%$ (Purser and Hanley, 1978; pers commun), background samples preceded by samples of twice modern activity would have a count rate of over $5 \sigma$ above background. Any cleaning of the reaction vessel in addition to the techniques described above would be expected to reduce memory only marginally. The solutions apparent for eliminating the memory problem in sample preparation for accelerator dating are 1) use of a new low carbon stainless steel reaction vessel for each sample, 2)

TABLE 3

Expected effect on the count rate of a background sample by a preceding sample having a twice modern count rate (20.6 $\pm 1 \mathrm{cpm} / \mathrm{g} \mathrm{C}_{6} \mathrm{H}_{6}$ at $70 \%$ efficiency)

\begin{tabular}{cccc}
\hline $\mathbf{f}$ & $\begin{array}{c}\text { Net activity of } \\
\text { 4g benzene } \\
\text { sample }(\mathrm{cpm})\end{array}$ & $\begin{array}{c}\text { Net specific } \\
\text { activity } \\
\left(\mathrm{dpm} / \mathrm{g} \mathrm{C}_{6} \mathrm{H}_{3} \pm 1 \sigma\right)\end{array}$ & $\begin{array}{c}\text { Apparent age of } \\
\text { background sample in } \\
\text { radiocarbon years BP }\end{array}$ \\
\hline 0.0014 & $0.10 \pm 0.09$ & $0.04 \pm 0.03$ & $46,000+11,000$ \\
0.0043 & $0.30 \pm 0.09$ & $0.11 \pm 0.03$ & $38,000 \pm 2600$ \\
0.0020 & $0.12 \pm 0.09$ & $0.04 \pm 0.03$ & $46,000+11,000$ \\
$0.0103 *$ & $0.72 \pm 0.09$ & $0.26 \pm 0.03$ & $31,000 \pm 1000$ \\
\hline
\end{tabular}

* Results obtained from reaction vessel with pitted inner surface. 


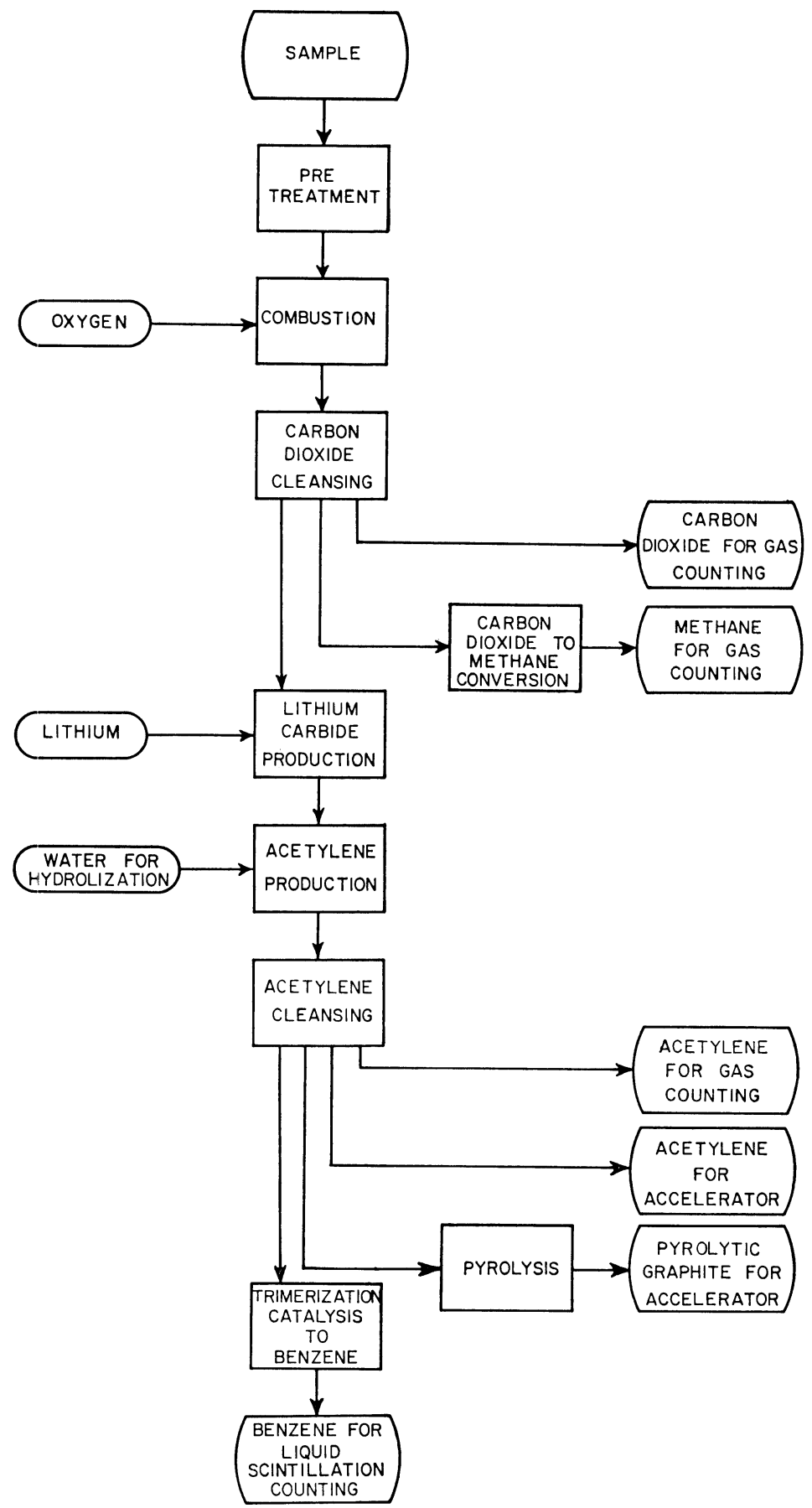

Fig 5. Processing of sample from original form into various compounds for ${ }^{14} \mathrm{C}$ 
lining or impregnating the vessel with some carbon-impermeable alloy or material, or 3) using a disposable liner of such a material to separate the stainless steel from the molten lithium. One such material might be aluminized 304 stainless steel which resists carburization affected by molten sodium at temperatures up to $1600^{\circ} \mathrm{C}$ (Anderson and Sneesby, 1960). This problem will be further explored by the Regional Accelerator Facility research group of the Laboratory of Isotope Geochemistry at the University of Arizona.

\section{ACKNOWLEDGMENTS}

The funds for this research were supplied by the United Kingdom Atomic Energy Authority in the form of an Extra-Mural Research Grant and the experiments were carried out at AERE Harwell. NSF partially supported travel expenses for one of us (C J R) to the Tenth International Radiocarbon Conference. The authors would like to warmly thank Austin Long for his invaluable help with the manuscript.

\section{REFERENCES}

Agarwala, R P, Naik, M C, Anand, M S, and Paul, A R, 1970, Diffusion of carbon in stainless steels: Jour Nuclear Material, v 36, p 41-47.

Anderson, W J and Sneesby, G V, 1960, Carburization of austenitic stainless steel in liquid sodium: North American Aviation rept no. NAA-SR-5282, Sept 1, 1960

Natesan, K and Kassner, T F, 1970, Thermodynamics and kinetic aspects of carbon transport in sodium-steel systems: Jour Nuclear Material, v 37, p 223-235.

Pearson, G W, Pilcher, J R, Baillie, M G L, and Hillman, J, 1977, Absolute radiocarbon dating using a low altitude European tree-ring calibration: Nature, v 270, p 25-28.

Pulham, R J, Hubberstey, P, Down, M S, 1977, Chemical methods of purifying liquid lithium: AERE H4B 2669 Harwell progress rept, Sept 1977.

Purser, K H and Hanley, P R, 1978, A carbon-14 dating system, in Conference on on radiocarbon dating with accelerators, 1st, Proc: Rochester, N Y, Univ Rochester, p 165-186. 